\title{
A case of recurrent thanatophoric dwarfism
}

\author{
L. Thulasi Devi, Athul R. S.*
}

Department of Obstetrics and Gynecology, Military Hospital, Thiruvananthapuram, Kerala, India

\author{
Received: 28 February 2021 \\ Revised: 03 April 2021 \\ Accepted: 05 April 2021

\section{*Correspondence:} \\ Dr. Athul R. S., \\ E-mail: athulrajan9@gmail.com
}

Copyright: (C) the author(s), publisher and licensee Medip Academy. This is an open-access article distributed under the terms of the Creative Commons Attribution Non-Commercial License, which permits unrestricted non-commercial use, distribution, and reproduction in any medium, provided the original work is properly cited.

\begin{abstract}
An interesting case of Recurrent Thanatophoric Dwarfism in a Multigravida; reporting to this hospital in second trimester which was terminated. It was confirmed on anomalies scan and was lethal. Genetic testing of the couple was advised; however, they refused and were lost to follow up. Long-term survivors are rare and require aggressive intervention for complications. In such cases couple should be informed of prognosis and extensively counselled for termination based on complications in long-term survivors as reported in literature. Management should be done after counselling and consultation regarding complications, clinical course, and prognosis of the condition. Due considerations may be given based on the parent's desire for extreme life-support measures based on availability and affordability for provision of comfort care for the newborn. End of Life Support issues should be considered based on prevailing laws governing the nation.
\end{abstract}

Keywords: Congenital malformation, Lethal, Medical genetics, Thanatophoric dwarfism

\section{INTRODUCTION}

Thanatophoric Dwarfism (TD) is a congenital short-limb dwarfism syndrome that is usually lethal in the perinatal period and is classified into two variants based on the presence of curved femurs and long bones; patients with straight, comparatively long femurs are usually associated with severe cloverleaf skull deformity and are classified as TD type II (TD2), and TD cases with curved, short femurs in presence or absence of cloverleaf skull are classified as TD type I (TD1). ${ }^{1,2}$ These dysplasias are invariably lethal and most cases are now diagnosed antenatally on anomalies scan and terminated. Thanatophoric Dysplasia and Dwarfism are often used interchangeably for same disease variant and are acceptable.

\section{CASE REPORT}

A 27-year-old G4P2L0A 1 all previous FTND lady presented to us @POG $24^{+3}$ with USG finding of Thanatophoric dwarfis On USG findings there was: (a) Single, Live, Intrauterine Fetus in cephalic presentation at the time of examination. Fetal biometry corresponded to average age of 20 weeks 5 days (suggestive of FGR), Humeri, femora, tibia and right fibula appeared short (severe micromelia) (Figure 1-4); (b) Mild metaphyseal widening and bowing was noted in the distal femora (Telephone Receiver Femur) (Figure 5); (c) Bilateral hitch-hiker thumb with no polydactyly/ syndactyly (Figure 6); (d) Bilateral clavicles showed Cleidocranial dysplasia(Figure 7); (e) Frontal bossing with mid face hypoplasia and nasal depression was noted (Figure 8); (f) Mild altered skull morphology was noted (Cloverleaf skull); the temporal lobes showed characteristic findings of temporal lobe dysplasia (TLD) including prominent sulcations and radially directed gyrations (Figure 9); (g) Long and narrow thorax noted. Thoracic dimensions were much smaller compared to the abdomen. Persistent lumbar kyphosis was noted with no other obvious abnormalities in the spinal column. (Figure10); (h) Bilateral mild pyelectasis was seen with no molyhydramnios, Features were suggestive of skeletal dysplasia; (i) Differential Diagnosis on USG was Thanatophoric Dwarfism and Achondroplasia. Patient had 
two previous live births, both females with same malformation, who expired after approximately 5 months with a confirmed diagnosis of Thanatophoric Dwarfism from Medical Genetics Department of AIIMS (New Delhi). She also gave history of one MTP after second trimester anomalies scan with findings suggestive of Thanatophoric Dwarfism. Patient was spouse of a health care worker and was aware of the lethal condition in present pregnancy. Couple was advised consultation with geneticist previously; however, it was refused. They were counselled again for consultation by Medical Geneticist; however, they refused and requested for termination which was done with consent. Patient did not allow us to take pictures of abortus and did not give consent for pathological or genetic evaluation on abortus. She had an uneventful recovery and was discharged.

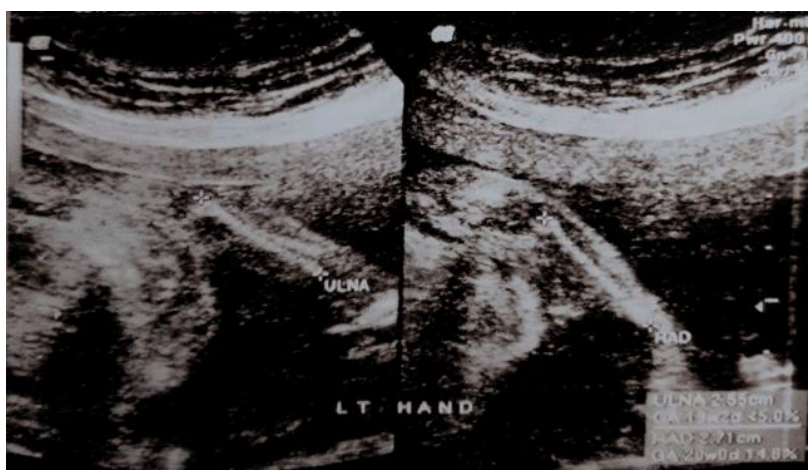

Figure 1: Short left radius and ulna with micromelia.

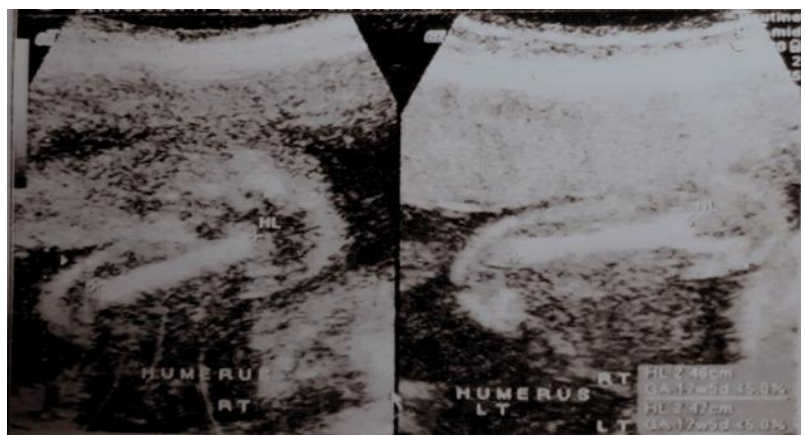

Figure 2: Short left and right humerus with micromelia.

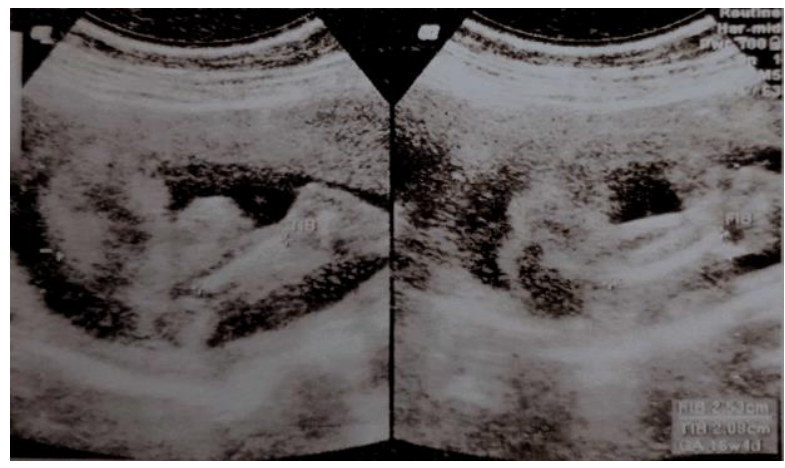

Figure 3: Short left tibia and fibula with micromelia.

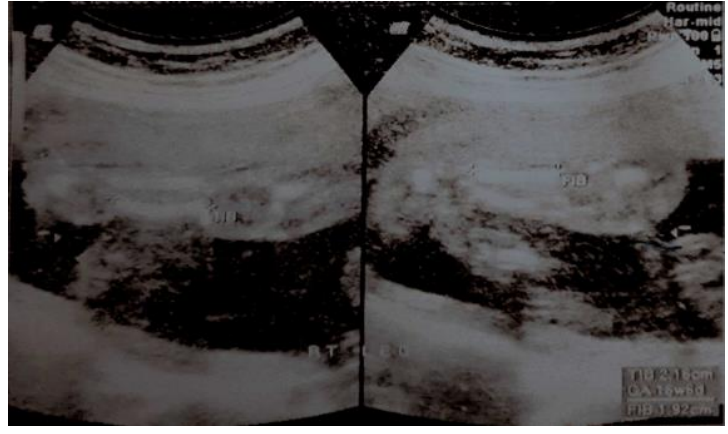

Figure 4: Short right Tibia and Fibula with micromelia.

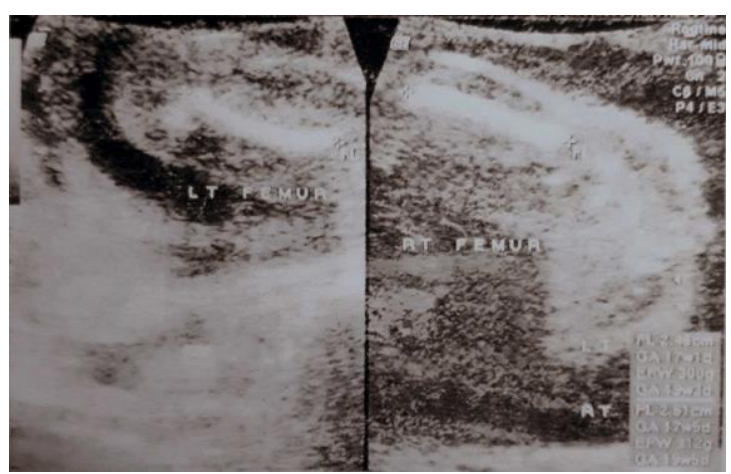

Figure 5: Left and right femur with metaphyseal widening and bowing (telephone receiver femur).

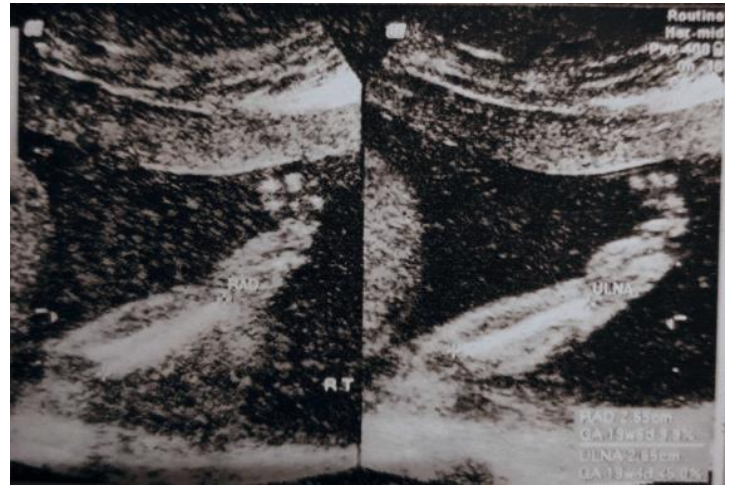

Figure 6: Right radius and ulna with hitchhiker thumb.

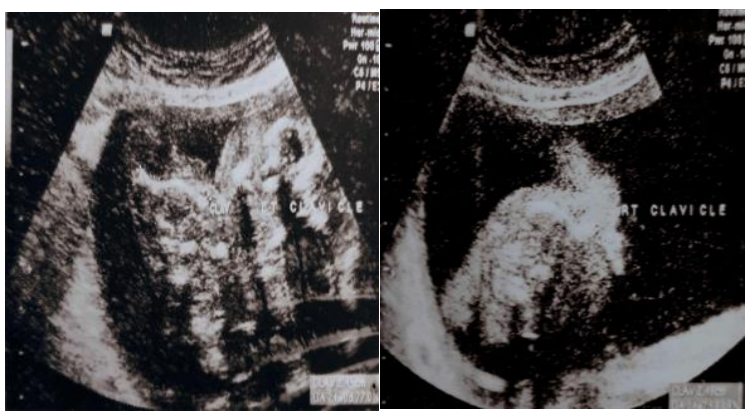

Figure 7: Left and right clavicle with cleidocranial dysplasia. 


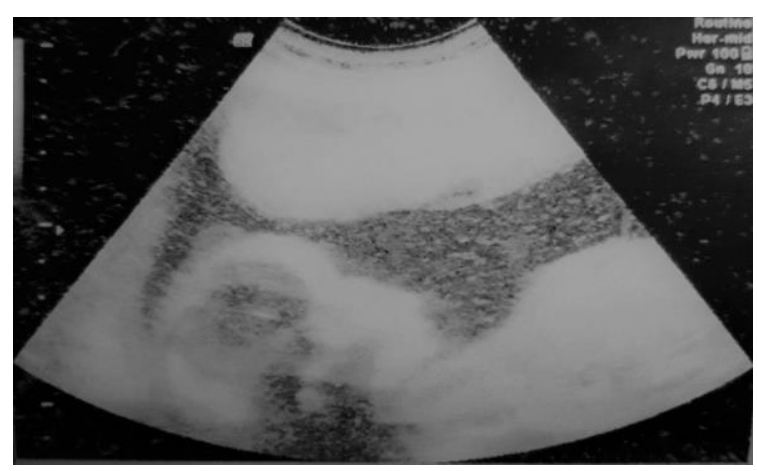

Figure 8: Fetal skull with frontal bossing, midline hypoplasia and nasal depression.

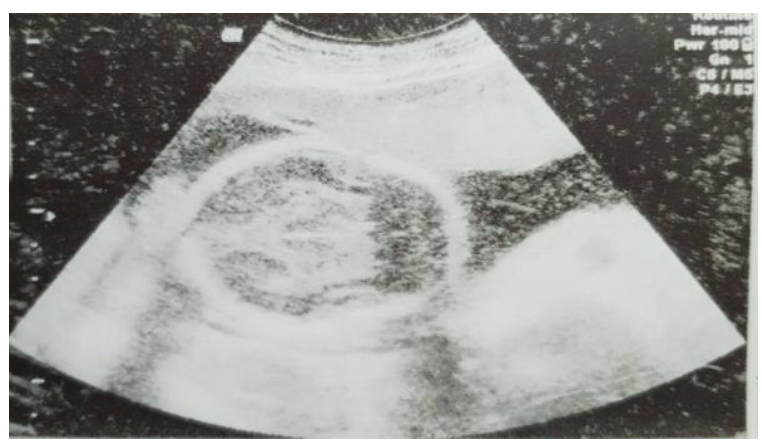

Figure 9: Fetal skull with altered morphology (cloverleaf skull) and temporal lobe dysplasia (TLD).

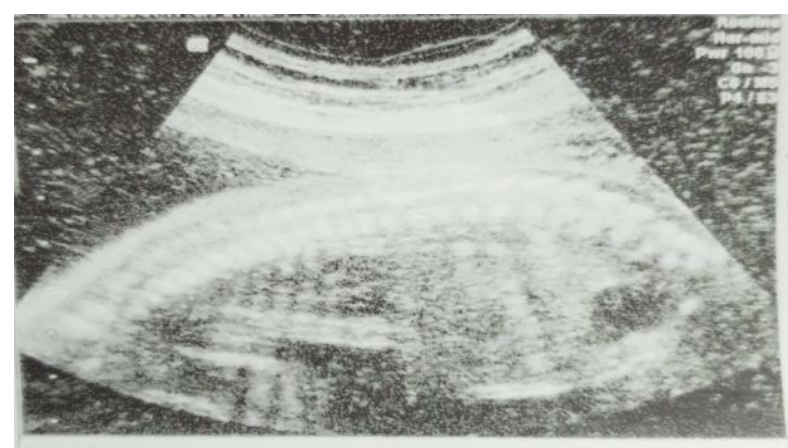

Figure 10: Fetal spine with persistent kyphosis.

\section{DISCUSSION}

Thanatophoric is Greek word translated as "death bearing" wherein children are usually stillborn due to respiratory failure. A few cases survive into childhood, with multiple medical disorders which is beyond scope of this discussion. Survivors have difficulty in spontaneous respiration and require respiratory or invasive ventilatory support with tracheostomy. Spinal stenosis and seizures are common manifestations. This lethal condition is recorded in approximately 1 in 60,000 births. Antenatal Ultrasound images of the ribs occasionally appear asymmetrical which is not present clinically. This leads to a erroneous diagnosis of Osteogenesis Imperfecta (OI) type II. A characteristic head shape mentioned as "kleeblattschädel" ("cloverleaf skull") is seen with Type 2 Thanatophoric Dwarfism.
Maroteaux et al. referred to neonates with micromelic dwarfism who were stillborn or died immediately after birth as having Thanatophoric Dwarfism. The ribs and bones of all extremities were very short and the vertebral bodies were considerably decreased in height with wide intervertebral spaces; caudal narrowing of the spinal canal was absent. Radiologically, the vertebral bodies were $\mathrm{H}$ shaped, and the femurs were shaped like telephone receivers. ${ }^{3,4}$ First reported cases in the literature, was by Maygrier. ${ }^{5}$ Antenatal diagnosis was initially demonstrated by Keats et al. ${ }^{6}$ Although antenatal ultrasound diagnosis of TD had been accomplished in the second trimester by Schild et al., it is not possible to emphatically distinguish between TD and other osteochondrodysplasias. ${ }^{7}$ Using restriction enzyme analysis, Sawai et al. identified a mutation in the FGFR3 gene in a fetus at 27 weeks' gestation. $^{8}$

Thanatophoric dwarfism is a congenital skeletal disorder in newborns with features of disproportionately small ribcage, rhizomelia/micromelia with folds of extra skin on the extremities. Other features of this syndrome include a wide narrow thorax, small ribs, underdeveloped lungs, macrocrania with frontal bossing and hypertelorism. Thanatophoric Dwarfism is divided into two subtypes. Type I is identified by extreme rhizomelia/micromelia, curved long bones of extremities, the iliac bones are short and wide with narrow thorax, normal trunk length and absent cloverleaf skull. The spine has platyspondyly with $\mathrm{H}$-shaped vertebrae and narrowing of the interpediculate distance, the cranium demonstrates a short base, and foramen magnum dimension is reduced. Features of prominent large forehead, Macrocrania and frontal bossing; hypertelorism (prominent wide spaced eyes) with a saddle nose may be present. Hands and feet are relatively normal, but fingers are short. Type II is characterized by short, straight long bones and cloverleaf skull. It presents with typical telephone-handle shaped long bones and $\mathrm{H}$ shaped vertebrae.

Pannier et al. reported a fetus with lethal TD1 diagnosed at 24 weeks gestation with severe dwarfism and the pregnancy terminated. Postmortem examination revealed cerebral cortical malformations with temporal lobe polymicrogyria and severe disorganization of growth plates in the long bones of extremities. Genetic analysis identified heterozygosity for 2 de novo missense mutations in the FGFR3 gene on the same allele (N540K and Q485R; 134934.0034). The authors also noted that the N540K mutation in isolation (134934.0010) results in the less severe phenotype of hypochondroplasia $(\mathrm{HCH} ; 146000) .{ }^{9}$

Hersh et al. suggested that the gene mutant in TD might be on chromosome 1 or 10 because of the of a de novo 1:10 balanced translocation in a newborn. Possibility of genetic heterogeneity exists with one or more forms of TD due to mutations in a gene other than FGFR3, it is also postulated that balanced translocation was merely coincidental and the disorder was classified as TD type I and there was no cloverleaf skull. ${ }^{10}$ The diagnosis of TD is established in a 
proband with characteristic clinical and/or radiologic features and/or a heterozygous pathogenic variant in FGFR3 identified on molecular genetic testing. Formal diagnostic criteria for Thanatophoric Dwarfism (TD) have not been established as yet.

Radiological findings suggested TD should be suspected in a fetus with the following antenatal ultrasound findings, or a neonate with the following clinical and radiological findings. During first trimester: Shortening of the long bones, possibly visible as early as 12 to 14 weeks POG; increased nuchal translucency; (b) During second and third trimester: FGR with limb length below fifth percentile recognizable by 20 weeks POG; well-ossified spine and skull; platyspondyly; ventriculomegaly; narrow chest cavity with short ribs; polyhydramnios; Bowed femurs (TD type I); (c) Cranial anomalies: Cloverleaf skull. Craniosynostosis involving coronal, lambdoid, and sagittal sutures, resulting in a trilobed skull shape (in TD type II; occasionally in TD type I) with relative macrocephaly, frontal bossing and hypertelorism. ${ }^{11}$

\section{Genotype/Phenotype Correlations}

Wilcox et al. correlated clinical, radiological, and histologic findings in 91 cases with FGFR3 mutations from the International Skeletal Dysplasia Registry. Commonest mutation was R248C (134934.0005), present in $45(50 \%)$ cases, and the second most common mutation was Y373C (134934.0016), found in 18 cases (20\%). All of these patients had TD1 with hallmark clinical features of curved femora and few cases with cloverleaf skull. All 17 (19\%) patients with the K650E mutation (134934.0004) had TD2, with characteristic straight femora, craniosynostosis and presence of cloverleaf skull. TD1 patients with the Y373C mutation were found to have severe radiological findings than TD1 patients with R248C mutation, with significant phenotypic overlap between them. Histopathologically, all cases showed similar abnormalities, but those with the K650E mutation were found to have preservation of the growth plate. $^{12}$

Thanatophoric Dwarfism (TD) is an Autosomal Dominant disorder expressed by a de novo pathogenic variant with $100 \%$ penetrance. Delezoide et al. studied 18 Thanatophoric Dwarfism fetuses for FGFR3 expression in cartilage sections by in situ hybridization and IHC. Specific antibodies revealed high levels of FGFR3 in cartilage of TD fetuses with no increased level in the corresponding mRNA. The specific signal is identified in nucleus of proliferative and hypertrophic chondrocytes. On the basis of these findings along with abnormal expression of collagen type X (120110); in chondrocytes of hypertrophic Thanatophoric Dwarfism (TD), it has been postulated that it leads to constitutive activation of the receptor through formation of a stable dimer; which also corresponds with increased stability and balanced translocation into the nucleus, where it might interfere with terminal chondrocyte differentiation. ${ }^{13}$ Molecular genetic testing approaches can include a combination of gene targeted testing (targeted analysis, single gene testing, and multi gene analysis) and comprehensive genomic testing (exome sequencing, Whole genome/exome sequencing ) depending on the phenotype which is beyond the scope of this article and discussion as these tests are not available at this centre and database is not being maintained. Further reading is recommended of genetic reviews on TD. ${ }^{14}$

\section{CONCLUSION}

Diagnosis of TD is often antenatal and referral to a maternal-fetal medicine specialist for assessment and management advice is recommended. Genetic counselling is the process of providing individuals and families with information on the nature, inheritance, and implications of genetic disorders to help them make informed medical and personal decisions. The ideal time for determination of genetic risk and discussion of the availability of investigation based on family history is before pregnancy. DNA banking is the storage of DNA (extracted from white blood cells) for possible future use. It is likely that testing methodology and our understanding of genes, allelic variants, and diseases will improve in the future. Due consideration should be given to DNA banking of affected foetuses and their parents.

In high-risk pregnancies once the FGFR3 has been identified in a family member, prenatal testing and preimplantation genetic testing for TD are possible with whole exome sequencing. In Low-risk pregnancies routine antenatal ultrasound examination may identify skeletal findings (e.g., cloverleaf skull, very short extremities, and small thorax) that raise the possible diagnosis of TD in a fetus not known to be at risk. On diagnosis of lethal skeletal dysplasia antenatally, it is difficult to pinpoint a specific diagnosis. Consideration of molecular genetic testing and Whole Exomic Sequencing (WES) for FGFR3 pathogenic variants/mutations is recommended. Molecular genetic testing for the parents of a proband with an apparent denovo pathogenic variant or mutation to confirm their genetic status and to facilitate reliable recurrence risk assessment is advisable for better understanding of the disease and counselling.

\section{Funding: No funding sources \\ Conflict of interest: None declared \\ Ethical approval: Not required}

\section{REFERENCES}

1. Norman AM, Rimmer S, Landy S, Donnai D. Thanatophoric dysplasia of the straight-bone type (type 2). Clin Dysmorphol. 1992;1(2):115-20.

2. Langer LO Jr, Yang SS, Hall JG, Sommer A, Kottamasu SR, Golabi M, Krassikoff N. Thanatophoric dysplasia and cloverleaf skull. Am J Med Genet Suppl. 1987;3:167-79. 
3. Maroteaux, P., Lamy, M. Le diagnostic des nanismes chondro-dystrophiques chez les nouveau-nes. Arch. Franc. Pediat. 1968;25:241-62.

4. Maroteaux P, Lamy M, Robert JM. Thanatophoric dwarfism. Presse Med. 1967 Nov 22;75(49):2519-24.

5. Maygrier, $\mathrm{C}$ Imaging of the Placenta: A Multimodality Pictorial Review. Bull. Soc. Obstet. Gynec.1898;1:248-55.

6. Keats TE, Riddervold HO, Michaelis LL. Thanatophoric dwarfism. Am J Roentgenol Radium Ther Nucl Med. 1970;108(3):473-80.

7. Schild RL, Hunt GH, Moore J, Davies H, Horwell DH. Antenatal sonographic diagnosis of thanatophoric dysplasia: a report of three cases and a review of the literature with special emphasis on the differential diagnosis. Ultrasound Obstet Gynecol. 1996;8(1):62-7.

8. Sawai H, Komori S, Ida A, Henmi T, Bessho T, Koyama K. Prenatal diagnosis of thanatophoric dysplasia by mutational analysis of the fibroblast growth factor receptor 3 gene and a proposed correction of previously published PCR results. Prenat Diagn. 1999;19(1):21-4.

9. Pannier S, Martinovic J, Heuertz S, Delezoide AL, Munnich A, Schibler L, et al. Thanatophoric dysplasia caused by double missense FGFR3 mutations. Am J Med Genet A. 2009;149A(6):1296-301.
10. Hersh JH, Yen FF, Peiper SC, Barch MJ, Yacoub OA, Voss DH, et al. De novo balanced translocation in an infant with thanatophoric dysplasia: a clue to the locus of the candidate gene. J Med Genet. 1995;32(4):2935 .

11. Khalil A, Pajkrt E, Chitty LS. Early prenatal diagnosis of skeletal anomalies. Prenat Diagn. 2011;31(1):11524.

12. Wilcox WR, Tavormina PL, Krakow D, Kitoh H, Lachman RS, Wasmuth JJ, et al. Molecular, radiologic, and histopathologic correlations in thanatophoric dysplasia. Am J Med Genet. 1998;78(3):274-81.

13. Delezoide AL, Lasselin-Benoist C, Legeai-Mallet L, Brice P, Senée V, Yayon A, Munnich A, et al. Abnormal FGFR 3 expression in cartilage of thanatophoric dysplasia fetuses. Hum Mol Genet. 1997;6(11):1899-06.

14. Adam MP, Ardinger HH, Pagon RA, Wallace SE, Bean LJH, Mirzaa G, et al. GeneReviews ${ }^{\circledR}$ [Internet]. Seattle (WA): University of Washington, Seattle; 1993-2021.

Cite this article as: Devi LT, Athul RS. A case of recurrent thanatophoric dwarfism. Int J Reprod Contracept Obstet Gynecol 2021;10:2091-5. 